Network Working Group

Request for Comments: 1619

Category: Standards Track
W. Simpson

Daydreamer

May 1994

PPP over SONET/SDH

Status of this Memo

This document specifies an Internet standards track protocol for the Internet community, and requests discussion and suggestions for improvements. Please refer to the current edition of the "Internet Official Protocol Standards" (STD 1) for the standardization state and status of this protocol. Distribution of this memo is unlimited.

\title{
Abstract
}

The Point-to-Point Protocol (PPP) [1] provides a standard method for transporting multi-protocol datagrams over point-to-point links. This document describes the use of PPP over synchronous optical Network (SONET) and Synchronous Digital Heirarchy (SDH) circuits.

This document is the product of the Point-to-Point Protocol Working Group of the Internet Engineering Task Force (IETF). Comments should be submitted to the ietf-ppp@merit.edu mailing list.

Applicability

This specification is intended for those implementations which desire to use the PPP encapsulation over high speed private point-to-point links, such as intra-campus single-mode fiber which may already be installed and unused. Because the PPP encapsulation has relatively low overhead, it is anticipated that significantly higher throughput can be attained compared to other SONET/SDH payload mappings, at a significantly lower cost for line termination equipment. 
Table of Contents

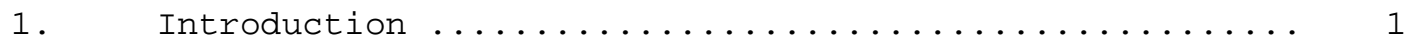

2. Physical Layer Requirements ................... 1

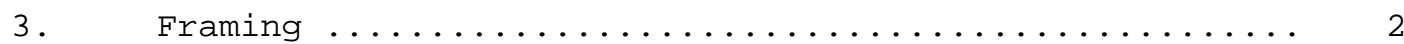

4. Configuration Details ...................... 3

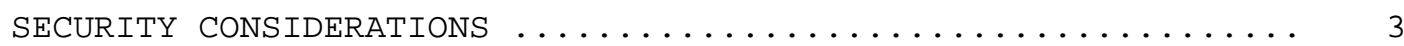

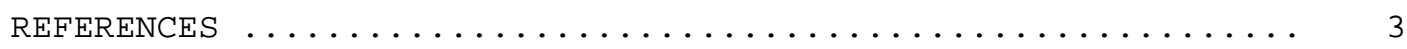

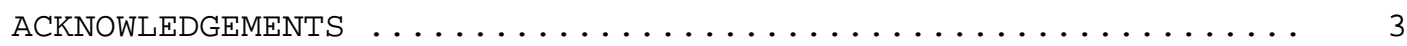

CHAIR'S ADDRESS $\ldots \ldots \ldots \ldots \ldots \ldots \ldots \ldots \ldots \ldots \ldots \ldots \ldots \ldots \ldots \ldots \ldots \ldots_{4}$

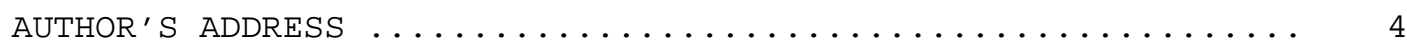


1. Introduction

PPP was designed as a standard method of communicating over pointto-point links. Initial deployment has been over short local lines, leased lines, and plain-old-telephone-service (POTS) using modems. As new packet services and higher speed lines are introduced, PPP is easily deployed in these environments as well.

This specification is primarily concerned with the use of the PPP encapsulation over SONET/SDH links. Since SONET/SDH is by definition a point-to-point circuit, PPP is well suited to use over these links.

The Synchronous Optical Network (SONET) [3] is an octet-synchronous multiplex scheme that defines a family of standard rates and formats. Despite the name, it is not limited to optical links. Electrical specifications have been defined for single-mode fiber, multi-mode fiber, and CATV 75 ohm coaxial cable. The transmission rates are integral multiples of $51.840 \mathrm{Mbps}$, which may be used to carry T3/E3 bit-synchronous signals. The allowed multiples are currently specified as

$\begin{array}{lrrr}\text { STS }-1 & 51.840 & \text { STS }-18 & 933.120 \\ \text { STS-3 } & 155.520 & \text { STS }-24 & 1,244.160 \\ \text { STS-9 } & 466.560 & \text { STS }-36 & 1,866.240 \\ \text { STS-12 } & 622.080 & \text { STS }-48 & 2,488.320\end{array}$

The CCITT Synchronous Digital Heirarchy (SDH) defines a subset of SONET transmission rates beginning at $155.520 \mathrm{Mbps}$ [5].

$\begin{array}{ll}\text { SONET } & \text { SDH equivalent } \\ \text { STS-3C } & \text { STM-1 } \\ \text { STS-12C } & \text { STM-4 } \\ \text { STS-48C } & \text { STM-16 }\end{array}$

2. Physical Layer Requirements

PPP treats SONET/SDH transport as octet oriented synchronous links. SONET/SDH links are full-duplex by definition.

Interface Format

PPP presents an octet interface to the physical layer. There is no provision for sub-octets to be supplied or accepted. 
The octet stream is mapped into the SONET/SDH Synchronous Payload Envelope (SPE), with the octet boundaries aligned with the SPE octet boundaries.

No scrambling is needed during insertion into the SPE.

The Path Signal Label (C2) is intended to indicate the contents of the SPE. The experimental value of 207 (cf hex) is used to indicate PPP.

The Multiframe Indicator (H4) is currently unused, and MUST be zero.

Transmission Rate

The basic rate for PPP over SONET/SDH is that of STS-3C/STM-1 at 155.520 Mbps. The available information bandwidth is 149.760 Mbps, which is the STS-3C/STM-1 SPE with section, line and path overhead removed. This is the same super-rate mapping that is used for ATM and FDDI [4].

Lower signal rates MUST use the Virtual Tributary (VT) mechanism of SONET/SDH. This maps existing signals up to T3/E3 rates asynchronously into the SPE, or uses available clocks for bitsynchronous and byte-synchronous mapping.

Higher signal rates SHOULD conform to the SDH STM series, rather than the SONET STS series, as equipment becomes available. The STM series progresses in powers of 4 (instead of 3 ), and employs fewer steps, which is likely to simplify multiplexing and integration.

Control Signals

PPP does not require the use of control signals. When available, using such signals can allow greater functionality and performance. Implications are discussed in [2].

3. Framing

The framing for octet-synchronous links is described in "PPP in HDLC Framing" [2].

The PPP frames are located by row within the SPE payload. Because frames are variable in length, the frames are allowed to cross SPE boundaries. 
4. Configuration Details

The standard LCP sync configuration defaults apply to SONET/SDH links.

The following Configuration Options are recommended:

Magic Number

No Address and Control Field Compression

No Protocol Field Compression

32-bit FCS

Security Considerations

Security issues are not discussed in this memo.

References

[1] Simpson, W., Editor, "The Point-to-Point Protocol (PPP)", RFC 1548, Daydreamer, December 1993.

[2] Simpson, W., Editor, "PPP in HDLC Framing", RFC 1549, Daydreamer, December 1993.

[3] "American National Standard for Telecommunications - Digital Hierarchy - Optical Interface Rates and Formats specification", ANSI T1.105-1991.

[4] "American National Standard for Telecommunications Synchronous Optical Network (SONET) Payload Mappings", ANSI T1.105.02-1993 draft.

[5] CCITT Recommendation G.707, "Synchronous Digital Hierarchy Bit Rates", June 1992. 
Acknowledgments

PPP over SONET was first proposed by Craig Partridge (BBN). Some information was obtained from the good folks at Bellcore.

Technical assistance and information was also provided by Victor Demjanenko (SUNY Buffalo).

Special thanks to Morning Star Technologies for providing computing resources and network access support for writing this specification.

\section{Chair's Address}

The working group can be contacted via the current chair:

Fred Baker

Advanced Computer Communications

315 Bollay Drive

Santa Barbara, California 93117

EMail: fbakereacc.com

Author's Address

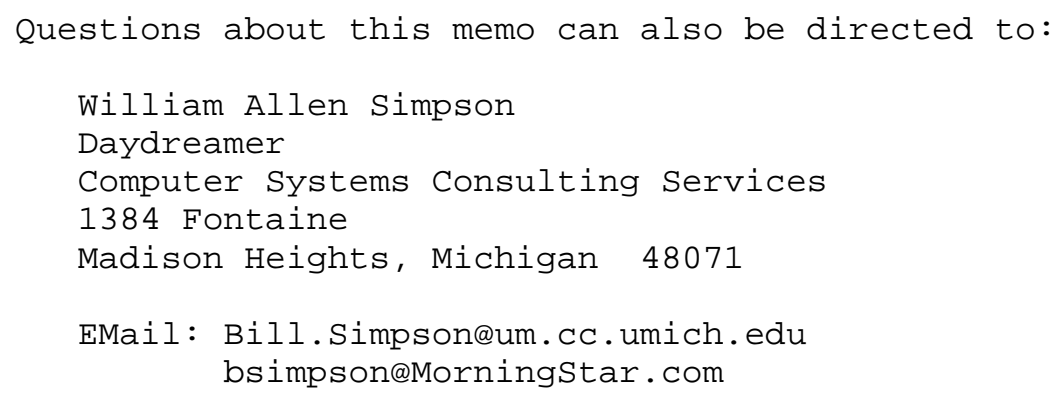

